\title{
Periodontology - A Waning or Winning Speciality!!!
}

\author{
Dr. Tarun Nanda, ${ }^{1}$ Dr. Sonia Nanda ${ }^{2}$ \\ ${ }^{1}$ Department of Periodontics, Bhojia Dental College, Baddi, Himachal Pradesh, India; \\ ${ }^{2}$ Department of Prosthodontics and Crown and Bridge, National Dental College, Derabassi, Punjab, India.
}

Tooth has carved a wonderful niche in the development and science of human body since ages. And along with it, revolves the study of gums known by the name periodontology. As a periodontist, one should aim to raise the standards of this speciality as a whole by showcasing its importance in clinics. Firstly, one can do this by determining the importance of perio-systemic relationship, that is, the role of periodontitis in diseases such as diabetes mellitus, cardiovascular diseases, pregnancy, stress, etc., to the patients. If a cardiologist or a gynaecologist refers the patient to a periodontist for checkup and treatment, then the role of periodontist in preventing heart attacks and preterm low birth will grow manifold in the society. And moreover, adding the feathers of doing implants in the field of periodontics will further strengthen the value of speciality on the forefront.

The area where periodontology as a speciality is lagging behind is the referral system by the general practitioners (GP's) and other co-professionals of other specialities. It can be due to various reasons. Primarily, due to mushrooming of numerous dental colleges, there is presence of half-baked, deficient in knowledge and expertise undergraduates. They lack in diagnosing the periodontal disease and even if they diagnose, they complete the non-surgical part by themselves and defer or avoid the surgical part. As a result, the patient is not referred to a periodontist. ${ }^{1}$

Adding to it, the BDS graduates are not taught in detail the time at which they should refer the patient to a periodontist. ${ }^{2}$ Most of the dentists usually refer the patient when one has an advanced level of periodontitis. So, in this area we have to pull our socks and teach our students the best time to refer the patient so that the credit of the periodontist in saving

\footnotetext{
Correspondence:

Dr.. Sonia Nanda

Department of Prosthodontics and Crown and Bridge,

National Dental College, Derabassi, Punjab, India.

email:drsonia84@gmail.com

Citation

Nanda T, Nanda S. Periodontology - A waning or winning speciality. J Nepal Soc Perio Oral Implantol. 2019;3(5):40
}

the teeth should be maintained. As dental insurance is still in a nascent stage in our scenario, so the patients hesitate for going to a specialist. ${ }^{3}$ We should make people aware regarding the role of periodontists as in the cases of medical field where an eye is operated upon by only eye surgeon, a kidney is treated only by a nephrologist not a GP and so on.

According to the surveys done on the national as well as on the international level, the prevalence of periodontitis is increasing in comparison with the population. ${ }^{4}$ Mostly the non-surgical therapy in the form of scaling and root planing along with administration of antibiotics and minor surgical procedures in the field of periodontics is done by the general dentist or the dental hygienists themselves. So, the domain of periodontal referral system should be reanalysed to ensure that the patient gets the best possible treatment and the practice of periodontists can mushroom further.

There are many procedures in our speciality that has remained the same over the years. Whether it is flap surgery or gingival depigmentation, it is the same. There are other areas in our field where we have gained such as lasers, microsurgery, newer regenerative materials, tissue engineering, and much more. One should practise and apply these new procedures in the treatment of periodontitis in our clinics to the fullest. Though the basic treatment of gingivitis or periodontitis remains the same, it is the advanced surgical area that can be improved upon. The GP's and other speciality professionals can be guided of the different procedures via seminars, group discussions, continuing dental education programs and lectures from time to time.

To conclude, one can say that in spite of numerous hurdles and difficulties, a periodontist will probably never run out of the patients in a clinical setting. He/she should be looked upon as a person who is an educator of good oral health, one who can diagnose and link various systemic diseases before they become malignant and preserve the dentition as a whole be it natural or in the form of titanium prosthesis. ${ }^{5}$ According to some, periodontology can be a dying speciality but to us it is the one with many aspects, roles and outreach. If the dentistry is evolving, so are we. So the future is exciting!!!

\section{REFERENCES}

1. Halemani S, Sanikop S, Patil S, Jalli V. Perception regarding factors related to periodontal therapy among general dental practitioners of Belgaum city - a questionnaire survey. Oral Health Prev Dent. 2014; 12(2):183-9.

2. Serio FG. Periodontics as a Specialty. Here Today, Gone Tomorrow? Musings of a 25-Year Traveler. Inside Dentistry 2009; 5(9).

3. Flemmig TF, Beikler T. Economics of periodontal care: market trends, competitive forces and incentives. Periodontol 2000. 2013;62(1):287-304.

4. Lee JH, Bennet DE, Richards PS, Inglehart MR. Periodontal referral patterns of general dentists: lessons for dental education. J Dent Educ. 2009;73(2):199-210.

5. Chang PK, Hall J, Finkelman M, Park A, Levi PA Jr. A survey: how periodontists and other dental professionals view the scope of periodontics. J Periodontol. 2014;85(7):925-33. 